\title{
Analysis of Rainfall Intensity-Duration-Frequency Relationship for Rwanda
}

\author{
Negash Wagesho ${ }^{*}$, Marie Claire ${ }^{2}$ \\ ${ }^{1}$ Department of Water Resources \& Irrigation Engineering, Arba Minch University, Arba Minch, Ethiopia \\ ${ }^{2}$ Ministry of Defense, Kigali, Rwanda \\ Email: *nwagesho@gmail.com, muclear2000@yahoo.fr
}

Received 23 March 2016; accepted 13 June 2016; published 16 June 2016

Copyright (C) 2016 by authors and Scientific Research Publishing Inc.

This work is licensed under the Creative Commons Attribution International License (CC BY). http://creativecommons.org/licenses/by/4.0/

(c) (i) Open Access

\begin{abstract}
Global atmospheric and oceanic perturbations and local weather variability induced factors highly alter the rainfall pattern of a region. Such factors result in extreme events of devastating nature to mankind. Rainfall Intensity Duration Frequency (IDF) is one of the most commonly used tools in water resources engineering particularly to identify design storm event of various magnitude, duration and return period simultaneously. In light of this, the present study is aimed at developing rainfall IDF relationship for entire Rwanda based on selected twenty six (26) rainfall gauging stations. The gauging stations have been selected based on reliable rainfall records representing the different geographical locations varying from 14 to 83 years of record length. Daily annual maximum rainfall data has been disaggregated into sub-daily values such as $0.5 \mathrm{hr}, 1 \mathrm{hr}, 3 \mathrm{hr}, 6 \mathrm{hr}$ and $12 \mathrm{hr}$ and fitted to the probability distributions. Quantile estimation has been made for different return periods and best fit distribution is identified based on least square standard error of estimate. At-site and regional IDF parameters were computed and subsequent curves were established for different return period. The moment ratio diagram (MRD) and L-moment ratio diagram (LMRD) methods have been used to fit frequency distributions and identify homogeneous regions for observed 24-hr maximum annual rainfall. The rainfall stations have been divided into five homogeneous rainfall regions for all 26 stations. The results of present analysis can be used as useful information for future water resources development planning purposes.
\end{abstract}

\section{Keywords}

Intensity, Duration, Frequency, Maximum Rainfall, Regionalization, Rwanda

\footnotetext{
${ }^{*}$ Corresponding author.
} 


\section{Introduction}

Highly induced atmospheric water vapour content as result of raising global temperature resulted in increased maximum precipitation. The increasing precipitation intensity and magnitude is recognized to have a significant impact on disaster management efforts and pose challenging threat towards the efforts to meet the growing needs of the most vulnerable population in sub-Saharan parts of Africa.

Rainfall Intensity-Duration-Frequency (IDF) relationship is one among the plethora of tools used for planning, designing and operating water resource development infrastructures [1] [2]. It gives an idea on return period of rainfall intensity which can be expected within a defined period [3]-[7]. It also provides a concise information between the maximum intensity of rain that falls within a given period of time [8]-[10]. Annual maxima and magnitudes above certain threshold or partial duration series of rainfall data are commonly applied as input for IDF analysis [11]. Bougadis and Adamowski [12] used scale invariance concept of rainfall events to disaggregate rainfall data from low resolution to high resolution for use in intensity-duration-frequency analysis. Cheng \& Agha Kouchak [13] argues that stationary time series assumption may reduce the extreme precipitation magnitude and ultimately increases the flood risk.

Hydrological information like IDF relationship being the principal input of design of sewer systems and other hydraulic structures is not yet readily available in systematically organized relationships to the end users in Rwanda. The lack of systematic relationships between events leads the design of many water resources infrastructures to be based on inadequate and unreliable data and information. Therefore, drainage system and highways fail to accommodate the unprecedented flood magnitude and easily get ruined.

Rwanda known for land of thousand hills whereby non-uniform topographical formation coupled with maninduced activities favored the local fluctuations in rainfall pattern across the country. This in turn resulted in devastating flood destruction over the past couples of years. The country suffered serious floods, landslides and drought events linked to ENSO (El Niño Southern Oscillation) episodes. The 1997/1998 high rainfall devoured planation and resulted in other associated environmental damages. Similarly the 1999/2000 drought episode significantly affected the Bugesera, Umutara and Mayaga regions [14]. Heavy rainfall, in combination with natural factors like steep topography, resulted in significant socio-economic impacts in the country [15].

The present study is aimed at developing comprehensive IDF relationship for twenty six (26) selected meteorological stations in Rwanda (Figure 1) and clustering rainfall stations into homogeneous regions based on

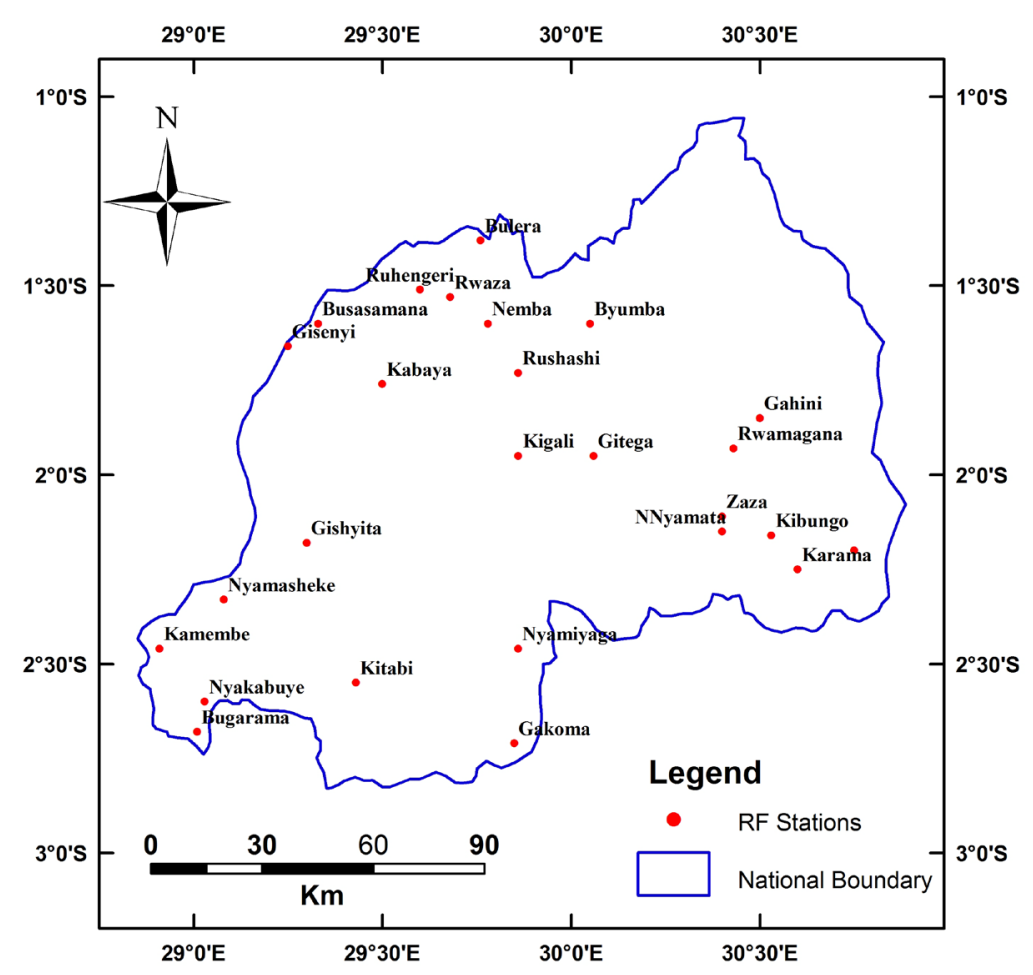

Figure 1. Selected meteorological stations for analysis in Rwanda. 
24-hrs annual maximum rainfall depth.

\section{The Study Area}

Rwanda is a small landlocked country in East African Great Lakes region. It lies within latitudes $1^{\circ} \mathrm{S}-3^{\circ} \mathrm{S}$ and longitudes $28^{\circ} \mathrm{E}-31^{\circ} \mathrm{E}$ having surface area of $26,338 \mathrm{~km}^{2}$. It is bordered with Uganda in the north and Tanzania in the east while in the south and west are Burundi and the Democratic Republic of Congo, respectively. The recent Population of Rwanda is growing fast and counts around 12 million according to the National Institute of Statistics of Rwanda. The divide between two of Africa's great watersheds, the Congo and Nile basins, extends from north to south through western Rwanda at an average elevation of 2743 meters [15]. Agriculture being the mainstay of the majority of the rural population, erratic equatorial rainfall pattern endangered the agricultural production. Even though Rwanda is situated in the equatorial rain-forest belt, it perceives a modified humid climate characterized by both equatorial rainforest and savannah type. The rainfall pattern is dominated by the subtropical anticyclone as a consequence of the Inter Tropical Convergence Zone positions permitting bimodal rainfall pattern to the region. Majority of the eastern belts of the country receive low seasonal rainfall and are characterized as drought prone areas.

\section{Materials and Methods}

Short to long period (14 - 83 years) daily observed rainfall records have been collected from Rwanda Meteorological Agency under Ministry of Natural Resources. The concise information of rainfall stations considered for present analysis are presented in Table 1 . The rainfall data at each stations has undergone through preliminary data scrutiny for consistency. Using stations spatial proximity principle missing daily rainfall records are accounted. Maximum daily rainfall magnitudes are disaggregated into sub-daily values of $0.5 \mathrm{hr}, 1 \mathrm{hr}, 3 \mathrm{hr}, 6 \mathrm{hr}$ and $12 \mathrm{hr}$. Multiples of probability distributions are used to fit the sample data for selected rainfall durations so as to reinforce the statistical argument. In this case, Normal distribution, Extreme Value-I distribution, two parameter Gamma distribution, Log Pearson Type III distribution and two parameter Log-normal distribution are used. Moment ratio diagram (MRD) and L-moment ratio diagram (LMRD) techniques are used to estimate parameters of the distribution and test the goodness of fit of probability distributions. The best fitted probability distribution is utilized to estimate the quantile estimates for different return period. Based on regional homogeneity analysis, stations having similar rainfall pattern are identified and the entire country is divided into five homogenous daily maximum rainfall zones.

\subsection{IDF Curve Parameter Estimation}

The intensity-duration-frequency relationship is established for each station and parameters of IDF curves are identified using the following relationship.

The typical generalized IDF parameters can be estimated using the following relationship [16].

$$
I=\frac{a}{(t+\gamma)^{c}}
$$

where $I=$ maximum intensity $(\mathrm{mm} / \mathrm{hr}) ; t=$ rainfall duration (min.); $\alpha=$ regression coefficient $(\mathrm{mm} / \mathrm{hr}) ; \gamma=$ time constant (min) and $c=$ exponent with values less than unity. In Equation (1) the constants $\gamma$ and $c$ do not depend on return period, however, the constants vary significantly with location and estimated for specific region. Converting Equation (1) into logarithmic form and reducing the sum of the squared deviation to minimum, we have,

$$
\begin{aligned}
& \ln I=\ln \alpha-C * \ln (t+\gamma) \\
& S=\sum_{i=1}^{n}[(\ln I-\{\ln a-C \ln (t+\gamma)\})]^{2}
\end{aligned}
$$

Equation (2) and (3) are utilized to compute the required intensities for respective stations and durations.

\subsection{Quantile Estimation}

The relationship between return period and probability of non-exceedence is expressed as: 
Table 1. Typical characteristics of rainfall stations under consideration.

\begin{tabular}{|c|c|c|c|c|c|c|c|}
\hline $\begin{array}{l}\text { S. } \\
\text { No. }\end{array}$ & $\begin{array}{l}\text { Rainfall } \\
\text { Stations }\end{array}$ & $\begin{array}{l}\text { East Longitude } \\
\text { (Degree) }\end{array}$ & $\begin{array}{l}\text { South Latitude } \\
\text { (Degree) }\end{array}$ & $\begin{array}{l}\text { Record } \\
\text { Period }\end{array}$ & $\begin{array}{l}\text { Record Length } \\
\text { (Years) }\end{array}$ & $\begin{array}{c}\text { Elevation } \\
\text { (m) }\end{array}$ & $\begin{array}{c}\text { Mean Annual } \\
\text { RF (mm) }\end{array}$ \\
\hline 1 & Gitega & 30.06 & 1.95 & $1969-2014$ & 46 & 1474 & 1069.7 \\
\hline 2 & Kigali & 29.86 & 1.95 & $1971-2014$ & 43 & 1490 & 1069.5 \\
\hline 3 & Nyamiyaga & 29.86 & 2.46 & $1957-2013$ & 57 & 1800 & 1198.1 \\
\hline 4 & Gakoma & 29.85 & 2.71 & $1986-2013$ & 28 & 1450 & 1159.2 \\
\hline 5 & Kitabi & 29.43 & 2.55 & $1984-2014$ & 31 & 2262 & 1832.2 \\
\hline 6 & Gishyita & 29.30 & 2.18 & $1981-2014$ & 32 & 1665 & 1539.5 \\
\hline 7 & Busasamana & 29.33 & 1.60 & 2001-2014 & 14 & 2055 & 1114.3 \\
\hline 8 & $\begin{array}{l}\text { Gisenyi } \\
\text { Airport }\end{array}$ & 29.25 & 1.66 & $1982-2014$ & 33 & 1554 & 1112.1 \\
\hline 9 & Kabaya & 29.5 & 1.76 & $1974-2014$ & 41 & 2292 & 1000.8 \\
\hline 10 & Bugarama & 29.01 & 2.68 & $1981-2014$ & 34 & 900 & 897.3 \\
\hline 11 & Kamembe & 28.91 & 2.46 & $1971-2014$ & 44 & 1591 & 1500.3 \\
\hline 12 & Nyakabuye & 29.03 & 2.60 & $1997-2014$ & 18 & 1400 & 1527.0 \\
\hline 13 & Nyamasheke & 29.08 & 2.33 & $1977-2014$ & 38 & 1527 & 1317.6 \\
\hline 14 & Nemba & 29.78 & 1.60 & $1987-2014$ & 28 & 1686 & 1535.7 \\
\hline 15 & Rushashi & 29.86 & 1.73 & 1979-2012 & 32 & 1650 & 1259.5 \\
\hline 16 & Ruhengeri & 29.60 & 1.51 & $1952-2014$ & 63 & 1860 & 1399.6 \\
\hline 17 & Rwaza & 29.68 & 1.53 & $1932-2014$ & 83 & 1800 & 1332.2 \\
\hline 18 & Bulera lac & 29.76 & 1.38 & $1947-2014$ & 68 & 1862 & 1134.7 \\
\hline 19 & $\begin{array}{l}\text { Byumba } \\
\text { meteo }\end{array}$ & 30.05 & 1.60 & $1996-2014$ & 19 & 2235 & 1332.5 \\
\hline 20 & Gahini & 30.5 & 1.85 & $1974-2014$ & 41 & 1534 & 1016.5 \\
\hline 21 & Zaza & 30.41 & 2.11 & $1945-2014$ & 70 & 1515 & 1138.60 \\
\hline 22 & Nyarubuye & 30.75 & 2.20 & $1958-2013$ & 56 & 1750 & 924.08 \\
\hline 23 & Kibungo & 30.53 & 2.16 & $1957-2012$ & 56 & 1680 & 1097.15 \\
\hline 24 & Karama & 30.60 & 2.25 & $1965-2014$ & 50 & 1347 & 915.66 \\
\hline 25 & Nyamata & 30.45 & 2.15 & $1982-2014$ & 33 & 1428 & 1084.79 \\
\hline 26 & Rwamagana & 30.43 & 1.93 & $1950-2014$ & 63 & 1535 & 1115.83 \\
\hline
\end{tabular}

$$
F=1-\frac{1}{T}
$$

where $F$ is the probability of an event having a magnitude of $X_{T}$ or less and the $T$-years magnitude is given by:

$$
X_{T}=\mu_{1}+K_{T} * \mu_{2}
$$

where $K_{T}$ is the frequency factor which is a function of return period and the parameter of the distribution and $\mu_{1}$ and $\mu_{2}$ are the moments of the distribution. The point estimate of certain quantile corresponding to a return period may be insignificant unless there is a proof of estimate of accuracy. The validity of estimated quantile checked by the standard error of estimate, $S_{T}$.

$$
S_{T}=\sqrt{\left[X_{T}-E\left(X_{T}\right)\right]^{2}}
$$

Standard error of estimate justifies error due to small sample, but it does not imply error due to inappropriate choice of distribution. The most efficient method of parameter estimation is the one which gives the least standard error of estimate. 


\subsection{Regionalization Rainfall Frequency Analysis}

The observed at-site hydrologic time series data are very short in length and hence substituting space for time is deployed to obtain representative average information about the region. The regional frequency analysis based on index flood method [17] [18], L-moments [19]-[22], region of influence [23], canonical correlation analysis [24] and others have been in use in literature. In the present study, the method suggested by Hosking and Wallis [25] is applied to identify candidate homogenous regions for maximum daily rainfall magnitudes. Invariant stations are identified by discordance measure. The MRD and LMRDs are estimated for all station based on the 24-hr maximum rainfall magnitude. Regionalization was made on statistical values (Cs, Ck, LCs, LCk) of maximum rainfall of the selected duration for each station based on the concept that stations in the same region are assumed to be drawn from similar parent distribution. Thus, similarity of the stations (Cs, Ck) and (LCs, LCk) plots to the theoretical probability distributions is accounted to classify the stations and determine the best fitting probability distribution helpful for subsequent quantile estimation.

\section{Results and Discussion}

\subsection{Estimation of IDF Parameters}

As available data in majority of the rainfall stations is daily record, reducing the available data in manageable sub-daily scale has been carried out using the uniform random disaggregation model. The disaggregated subdaily data is further statistically checked against the historical records for corresponding duration. It has been found that there is no statistically significant variability between the desegregated and historical observations for selected stations. The IDF parameters are computed for all 26 stations for return period of 2, 5, 10, 25, 50 and 100 years. The computed IDF parameters are presented in Table 2 . The parameters exhibit similarity over return period, however, there is no well-defined relationship with respect to station location. The IDF curves have been developed for all station for different return period (Figure 2). To aid water resources planners and decision

Table 2. Computed IDF parameters for selected (15) stations.

\begin{tabular}{|c|c|c|c|c|c|c|c|c|}
\hline S.N & Stations & Coefficiens & $T=2 \mathrm{yrs}$ & $T=5 \mathrm{yrs}$ & $T=10 \mathrm{yrs}$ & $T=25 \mathrm{yrs}$ & $T=50 \mathrm{yrs}$ & $T=100 \mathrm{yrs}$ \\
\hline \multirow{4}{*}{1} & \multirow{4}{*}{ Bugarama } & $\alpha$ & 1048.23 & 1650.65 & 1289.53 & 1109.04 & 1057.19 & 2169.15 \\
\hline & & $\gamma$ & 6.38 & 17.33 & 11.71 & 4.85 & 2.19 & 15.94 \\
\hline & & $C$ & 0.88 & 0.91 & 0.83 & 0.79 & 0.77 & 0.86 \\
\hline & & SEE & 1.82 & 0.56 & 2.53 & 2.32 & 2.00 & 1.55 \\
\hline \multirow{4}{*}{2} & \multirow{4}{*}{ Bulera } & $\alpha$ & 2250.96 & 2142.42 & 2480.84 & 2268.19 & 2846.76 & 2017.67 \\
\hline & & $\gamma$ & 20.56 & 19.80 & 19.57 & 17.33 & 18.55 & 11.71 \\
\hline & & C & 0.97 & 0.93 & 0.94 & 0.90 & 0.93 & 0.86 \\
\hline & & SEE & 1.84 & 1.84 & 1.81 & 2.11 & 1.84 & 2.49 \\
\hline \multirow{4}{*}{3} & \multirow{4}{*}{ Busasamana } & $\alpha$ & 1123.60 & 1373.92 & 1544.18 & 1831.31 & 2214.25 & 2532.86 \\
\hline & & $\gamma$ & 0.62 & 2.44 & 3.15 & 3.94 & 6.43 & 8.62 \\
\hline & & $C$ & 0.80 & 0.80 & 0.80 & 0.82 & 0.84 & 0.84 \\
\hline & & SEE & 0.77 & 0.83 & 0.79 & 0.95 & 0.78 & 1.28 \\
\hline \multirow{4}{*}{4} & \multirow{4}{*}{ Byumba } & $\alpha$ & 2155.87 & 1222.45 & 1078.97 & 1018.31 & 1068.94 & 1187.06 \\
\hline & & $\gamma$ & 28.94 & 11.58 & 4.85 & 0.05 & 0.02 & 0.02 \\
\hline & & $C$ & 0.95 & 0.85 & 0.82 & 0.80 & 0.79 & 0.80 \\
\hline & & SEE & 1.84 & 1.77 & 2.13 & 3.18 & 3.15 & 2.62 \\
\hline \multirow{4}{*}{5} & \multirow{4}{*}{ Gahini } & $\alpha$ & 366.08 & 2122.56 & 2206.10 & 2259.42 & 2460.77 & 2435.12 \\
\hline & & $\gamma$ & 0.00 & 22.42 & 20.56 & 18.55 & 16.85 & 13.71 \\
\hline & & $C$ & 0.68 & 0.91 & 0.92 & 0.91 & 0.92 & 0.91 \\
\hline & & SEE & 1.36 & 1.14 & 1.06 & 0.99 & 0.93 & 0.82 \\
\hline
\end{tabular}




\section{Continued}

\begin{tabular}{|c|c|c|c|c|c|c|c|c|}
\hline \multirow{4}{*}{6} & \multirow{4}{*}{ Gakoma } & $\alpha$ & 653.46 & 745.76 & 814.81 & 980.55 & 1037.34 & 1232.85 \\
\hline & & $\gamma$ & 0.02 & 0.05 & 0.05 & 0.05 & 0.05 & 0.62 \\
\hline & & C & 0.78 & 0.76 & 0.76 & 0.77 & 0.76 & 0.77 \\
\hline & & SEE & 4.44 & 4.02 & 4.31 & 4.41 & 4.49 & 3.90 \\
\hline \multirow{4}{*}{7} & \multirow{4}{*}{ Gisenyi } & $\alpha$ & 713.11 & 780.93 & 898.91 & 1231.39 & 1322.68 & 2015.57 \\
\hline & & $\gamma$ & 0.62 & 0.62 & 0.62 & 2.19 & 0.62 & 6.38 \\
\hline & & $C$ & 0.80 & 0.76 & 0.76 & 0.79 & 0.78 & 0.83 \\
\hline & & SEE & 4.52 & 3.28 & 3.70 & 1.74 & 2.67 & 2.36 \\
\hline \multirow{4}{*}{8} & \multirow{4}{*}{ Gishyita } & $\alpha$ & 743.60 & 1045.55 & 841.99 & 923.06 & 958.47 & 1029.51 \\
\hline & & $\gamma$ & 4.25 & 7.38 & 2.03 & 2.00 & 0.62 & 0.62 \\
\hline & & $C$ & 0.80 & 0.83 & 0.78 & 0.78 & 0.77 & 0.77 \\
\hline & & SEE & 2.87 & 3.04 & 2.79 & 3.20 & 2.99 & 3.00 \\
\hline \multirow{4}{*}{9} & \multirow{4}{*}{ Gitega } & $\alpha$ & 1351.90 & 1200.76 & 2087.7 & 2301.76 & 2533.42 & 2153.77 \\
\hline & & $\gamma$ & 13.94 & 7.63 & 13.14 & 10.25 & 9.23 & 4.22 \\
\hline & & $C$ & 0.90 & 0.86 & 0.93 & 0.93 & 0.93 & \\
\hline & & SEE & 1.17 & 1.29 & 1.21 & 1.04 & 0.93 & \\
\hline \multirow{4}{*}{10} & \multirow{4}{*}{ Kabaya } & $\alpha$ & 2312.29 & 1427.51 & 1482.56 & 1571.987 & 2369.535 & 2520.63 \\
\hline & & $\gamma$ & 26.03 & 11.85 & 8.32 & 3.94 & 11.86 & 8.61 \\
\hline & & $C$ & 0.97 & 0.87 & 0.86 & 0.85 & 0.88 & 0.88 \\
\hline & & SEE & 2.48 & 1.74 & 1.28 & 1.94 & 0.91 & 1.18 \\
\hline \multirow{4}{*}{11} & \multirow{4}{*}{ Kamembe } & $\alpha$ & 1222.07 & 1241.79 & 1181.43 & 1387.63 & 1199.10 & 1888.25 \\
\hline & & $\gamma$ & 13.94 & 8.61 & 4.61 & 4.85 & 0.62 & 8.22 \\
\hline & & $C$ & 0.86 & 0.84 & 0.81 & 0.81 & 0.77 & 0.83 \\
\hline & & SEE & 1.5228 & 2.4225 & 2.8966 & 3.3448 & 4.1961 & 2.9383 \\
\hline \multirow{4}{*}{12} & \multirow{4}{*}{ Karama } & $\alpha$ & 3525.93 & 3669.83 & 3419.79 & 3510.284 & 3648.82 & 3728.63 \\
\hline & & $\gamma$ & 47.83 & 45.31 & 35.89 & 29.36 & 27.42 & 23.03 \\
\hline & & C & 0.98 & 0.98 & 0.97 & 0.97 & 0.97 & 0.96 \\
\hline & & SEE & 1.69 & 1.63 & 1.39 & 0.95 & 0.81 & 0.68 \\
\hline \multirow{4}{*}{13} & \multirow{4}{*}{ Kibungo } & $\alpha$ & 3600.71 & 3617.14 & 3219.35 & 3564.30 & 3723.39 & 3729.97 \\
\hline & & $\gamma$ & 46.59 & 43.12 & 32.25 & 27.41 & 24.18 & 20.54 \\
\hline & & C & 0.97 & 0.97 & 0.95 & 0.95 & 0.95 & 0.95 \\
\hline & & SEE & 2.67 & 2.48 & 1.97 & 1.73 & 1.55 & 1.39 \\
\hline \multirow{4}{*}{14} & \multirow{4}{*}{ Kigali } & $\alpha$ & 1040.31 & 1592.58 & 2130.82 & 3047.59 & 4010.53 & 5792.70 \\
\hline & & $\gamma$ & 7.79 & 10.70 & 14.94 & 21.54 & 27.79 & 37.88 \\
\hline & & $C$ & 0.86 & 0.91 & 0.930 & 0.95 & 0.96 & 0.99 \\
\hline & & SEE & 1.34 & 2.02 & 1.17 & 0.35 & 0.67 & 1.35 \\
\hline \multirow{4}{*}{15} & \multirow{4}{*}{ Kitabi } & $\alpha$ & 1526.31 & 2708.73 & 3153.95 & 3665.86 & 4547.55 & 4377.41 \\
\hline & & $\gamma$ & 13.94 & 28.94 & 29.49 & 29.02 & 32.27 & 29.37 \\
\hline & & $C$ & 0.89 & 0.93 & 0.94 & 0.94 & 0.96 & 0.94 \\
\hline & & SEE & 0.99 & 0.74 & 0.70 & 0.74 & 0.76 & 0.73 \\
\hline
\end{tabular}




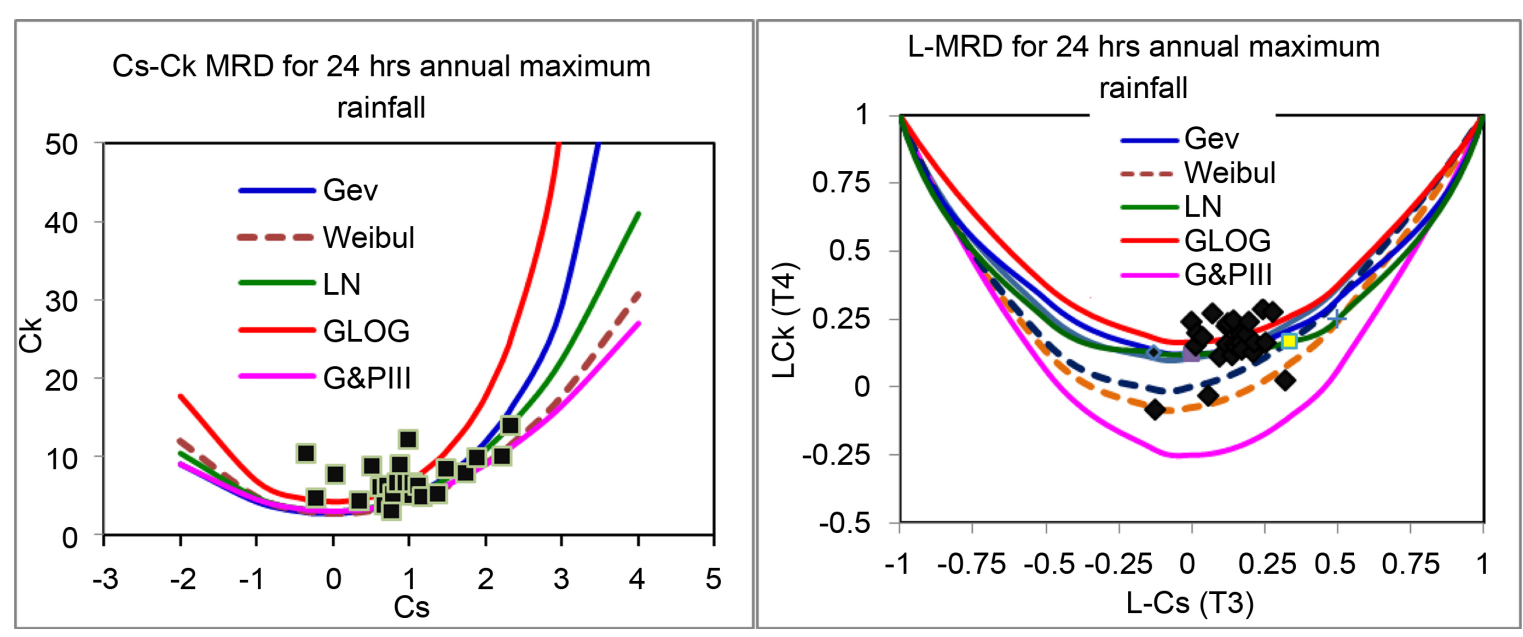

Figure 2. MRD and LMRD for 24 hrs maximum annual rainfall data.

makers, the interpolated IDF map is prepared for entire Rwanda based on 24-hrs annual maximum rainfall distribution for selected return period (Figure 3). These maps will assign particular rainfall intensity magnitude to particular points over the study area through spatial interpolation.

\subsection{Fitting Probability Distribution}

The 24-hrs annual maximum rainfall magnitude is subjected to MRD (Ck versus Cs) and LMRD (LCk versus LCs) plot whereby station information close enough to the theoretical distribution is assumed to fit the data well. Based on LMRD analysis, the General Logistic and General Extreme value distributions fits well for about 80\% of the stations. However, Pearson type-III, General logistic and Gamma distribution put in the front list for MRD case for majority of the stations (Figure 4). A diagram based on Cs \& Ck and LCs \& LCk are used to identify the appropriate distribution that fits the rainfall data. But L-moment ratios plot well separated and allows identifying of distribution.

\subsection{Regional Rainfall Frequency Analysis}

The conventional MRD and LMRD are primarily used to identify homogeneous regions for 24-hr annual maximum rainfall distribution. The L moment ratios (LCs and LCk) for each station based on specific duration rainfall is plotted against its regional averages on L-moment ratio diagrams. It is assumed that LCs, LCk values of one station varies linearly with LCs, LCk values of the neighboring station. A suitable parent distribution is that which averages the scattered data and around which the data spread consistently. The delineation result indicated that five (5) homogeneous regions were established. The transect starts with region-1 in the North-west part of the country and extends progressively to region- 5 in the South-east parts in the transverse direction. Region 1 includes the Bulera, Byumba, Nemba, Ruhengeri, Rushashi and Rwaza stations whereby the Generalized Logistic distribution fits well. This region covers a very limited North-west part of the country. Region-2 covers the Busasamana, Gisenyi, gishyita and Kabaya stations residing to the south of region-1.The Bugarama, Camembert, Kiitabi, Nyamasheke and Nyakabuye stations are categorized under region-3. Region-4 accounts for Gakoma, Gitega, Kigali and Nyamiyaga stations. All other stations are grouped into region 5, the south western region (Figure 5). The regression coefficient, $\alpha$ decreases as one moves from region- 1 to region-5. The rainfall stations grouped into particular regions and corresponding best fitting distributions are listed in Table 3.

The regional IDF parameters are estimated for five homogeneous regions. The regional IDF parameter values are tabulated in Table 4 and subsquent regional IDF curves are presented in Figure 6. The quantiles for stations belonging to specified region are estimated using the regional best fitted distribution (Table 5). The estimated quantiles are then pooled together to calculate the mean of those stations within the region for each return period and durations. It can be discerened that the IDF parameters adequately estimated rainfall intensities for various durations and return period and such results can be used as a preliminary information for water resources planning purposes. 

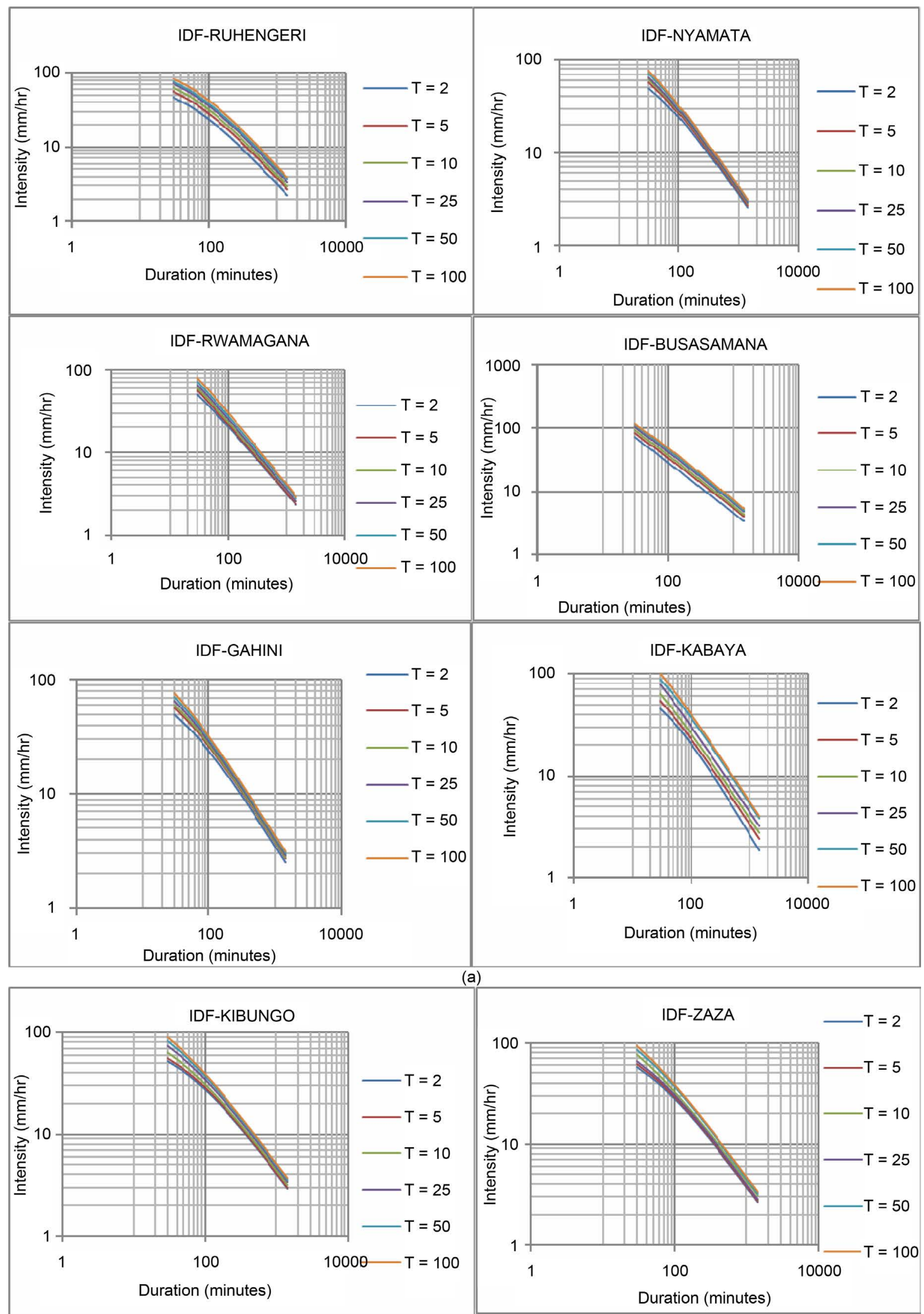

a)

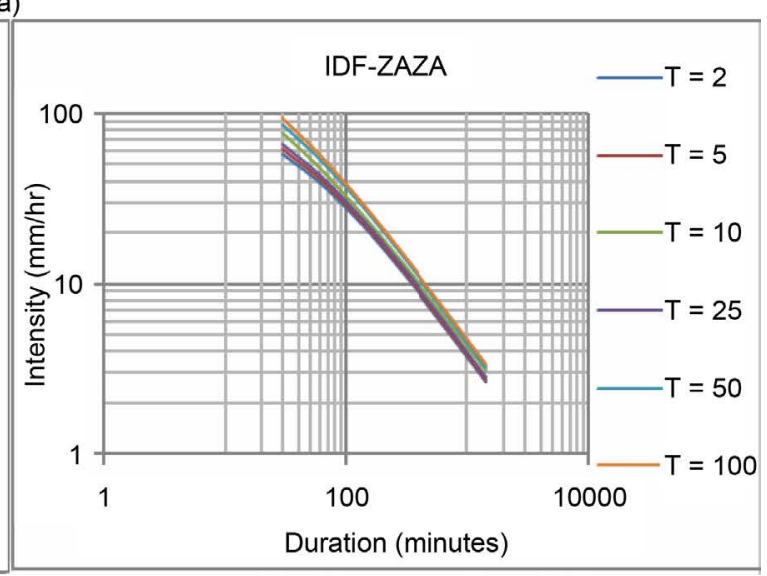



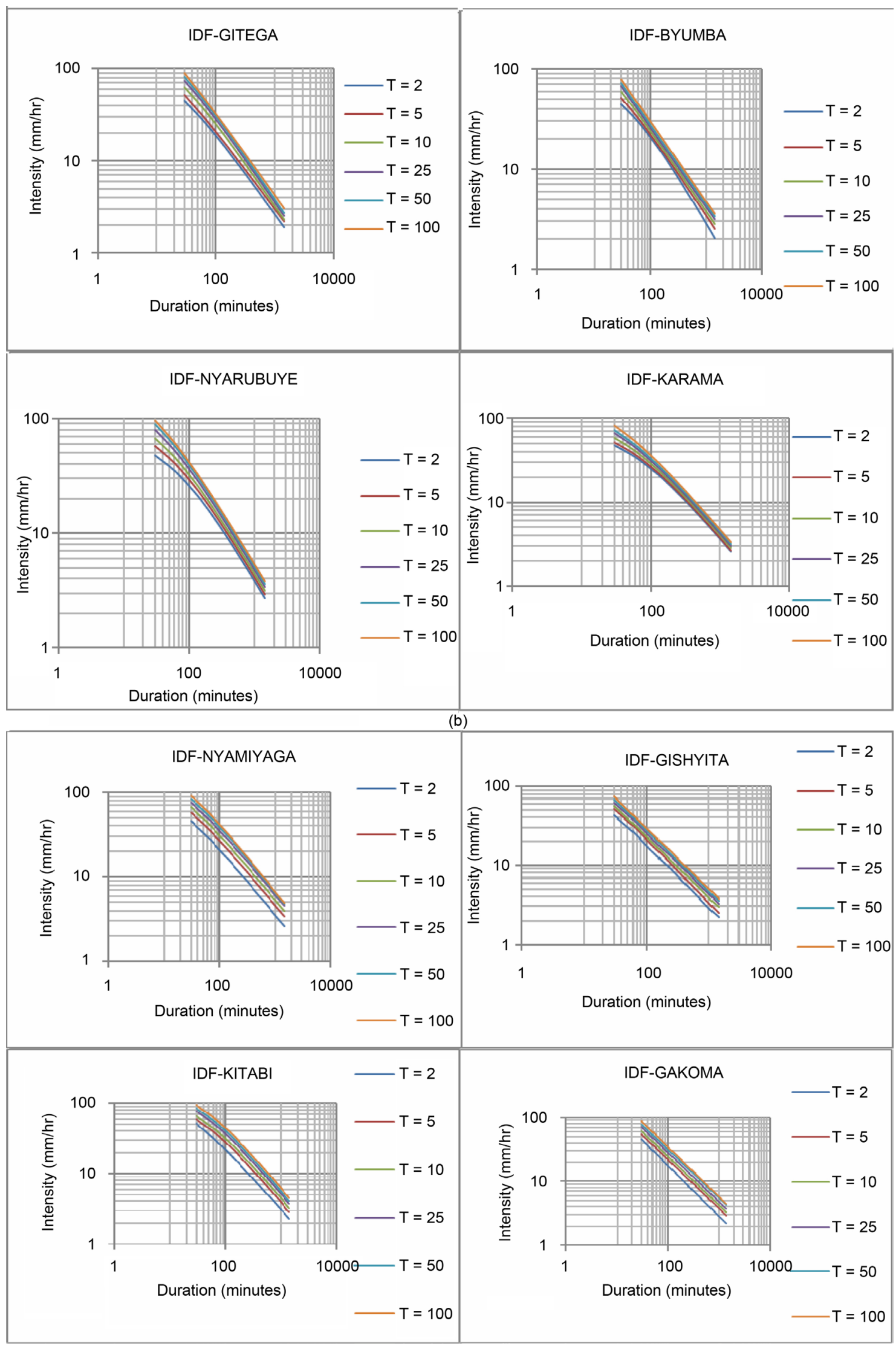

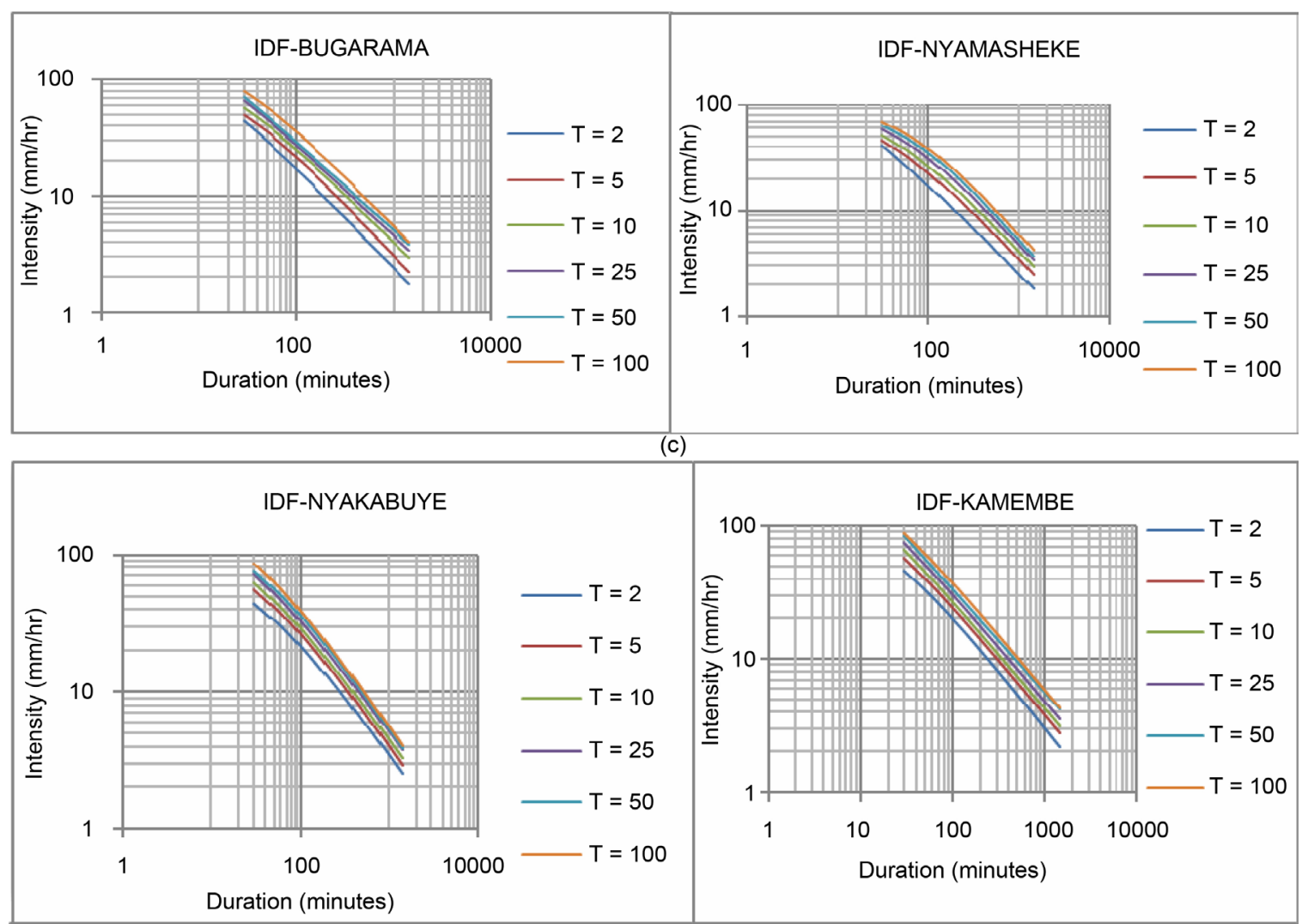

(c)
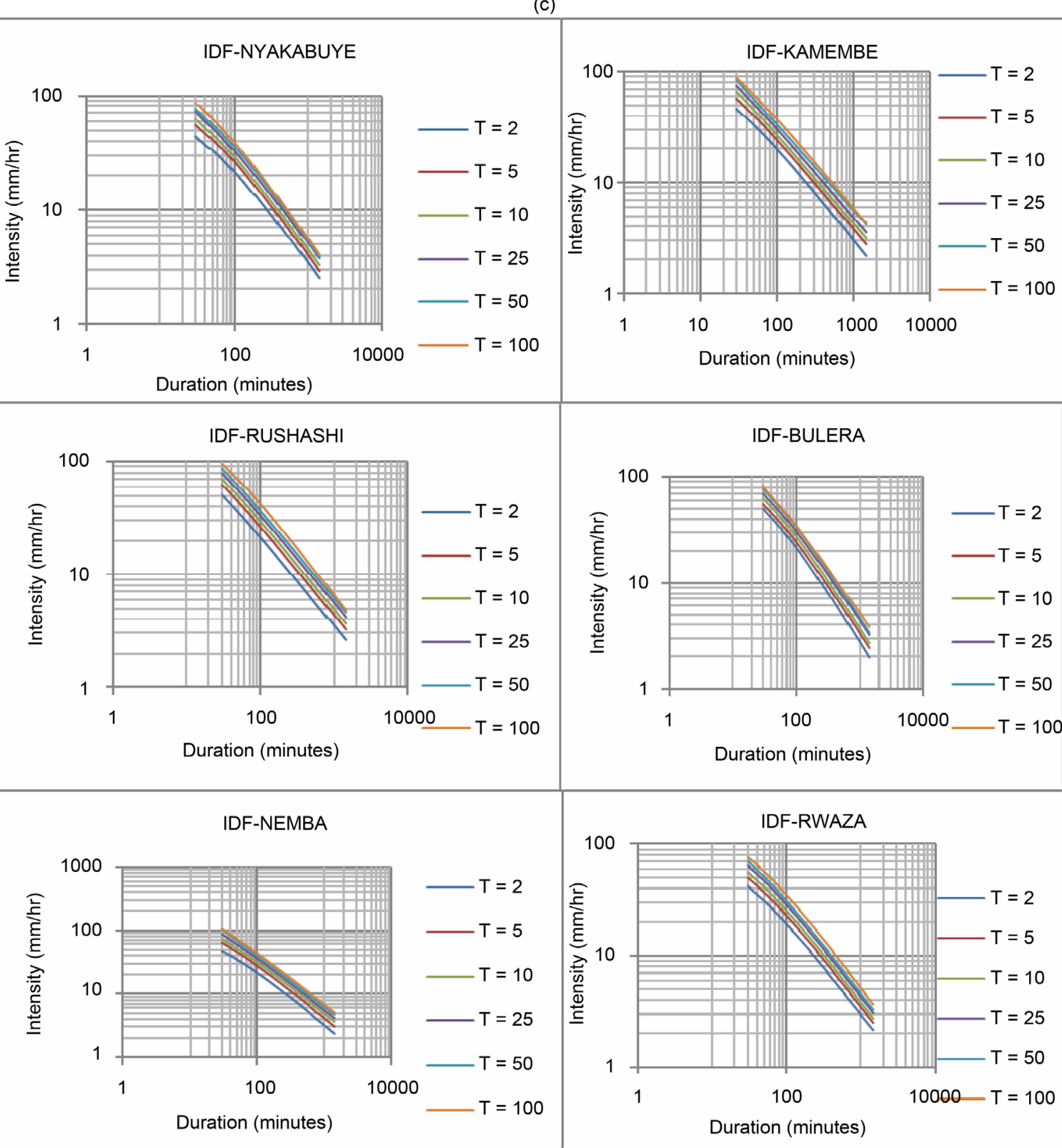

(d)

Figure 3. (a) (b) (c) (d) IDF curves developed for different stations. 


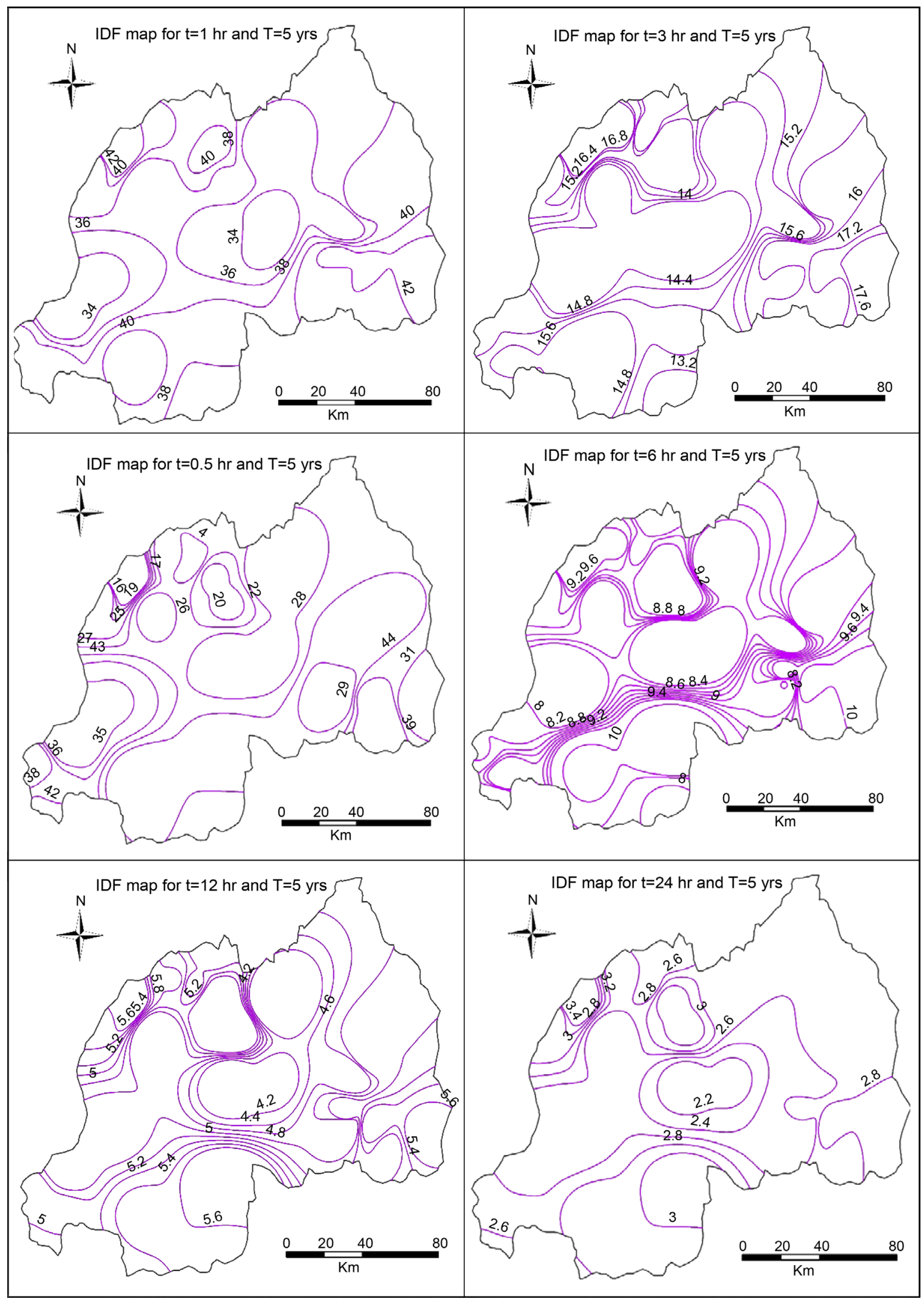

(a) 


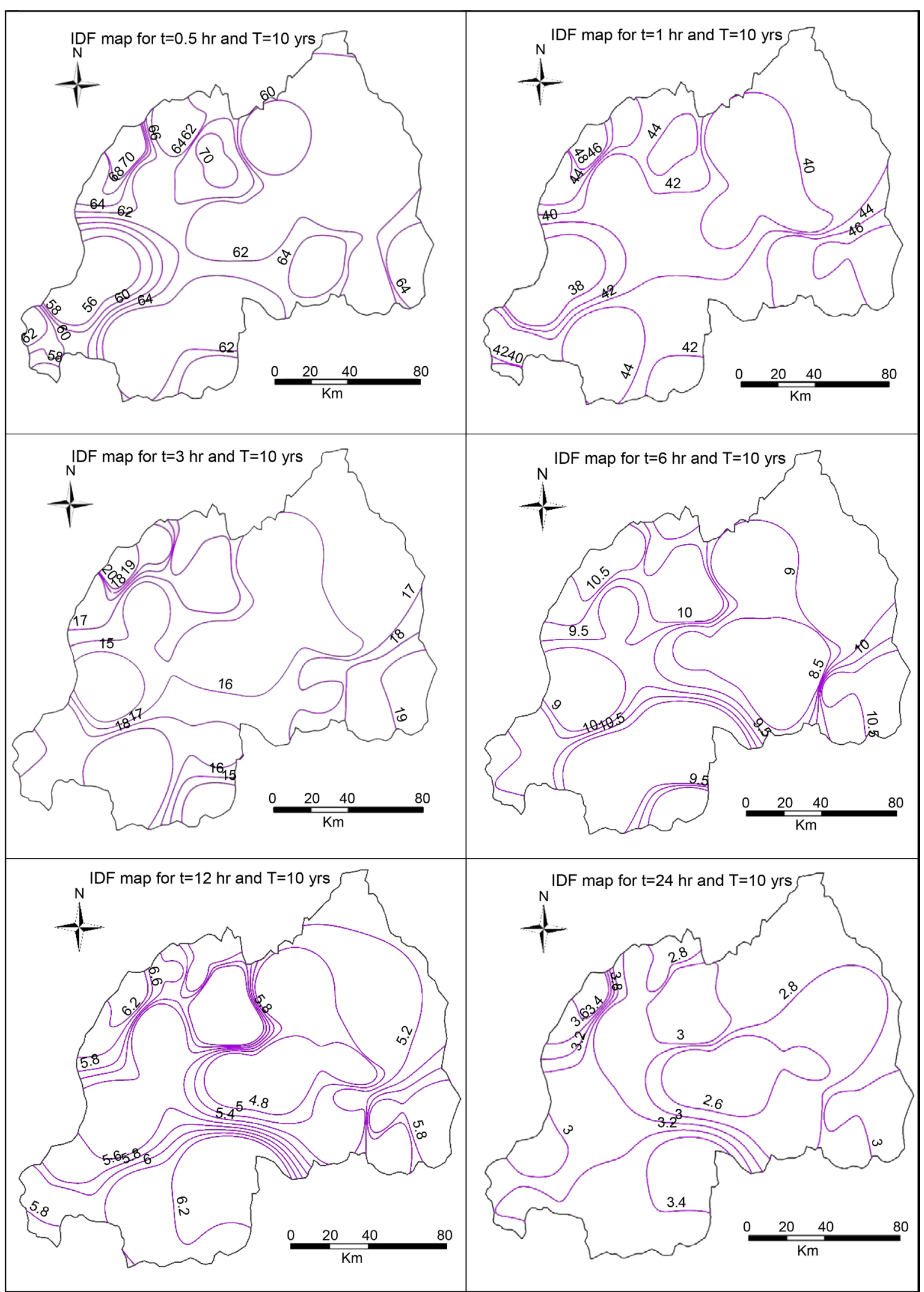

(b) 


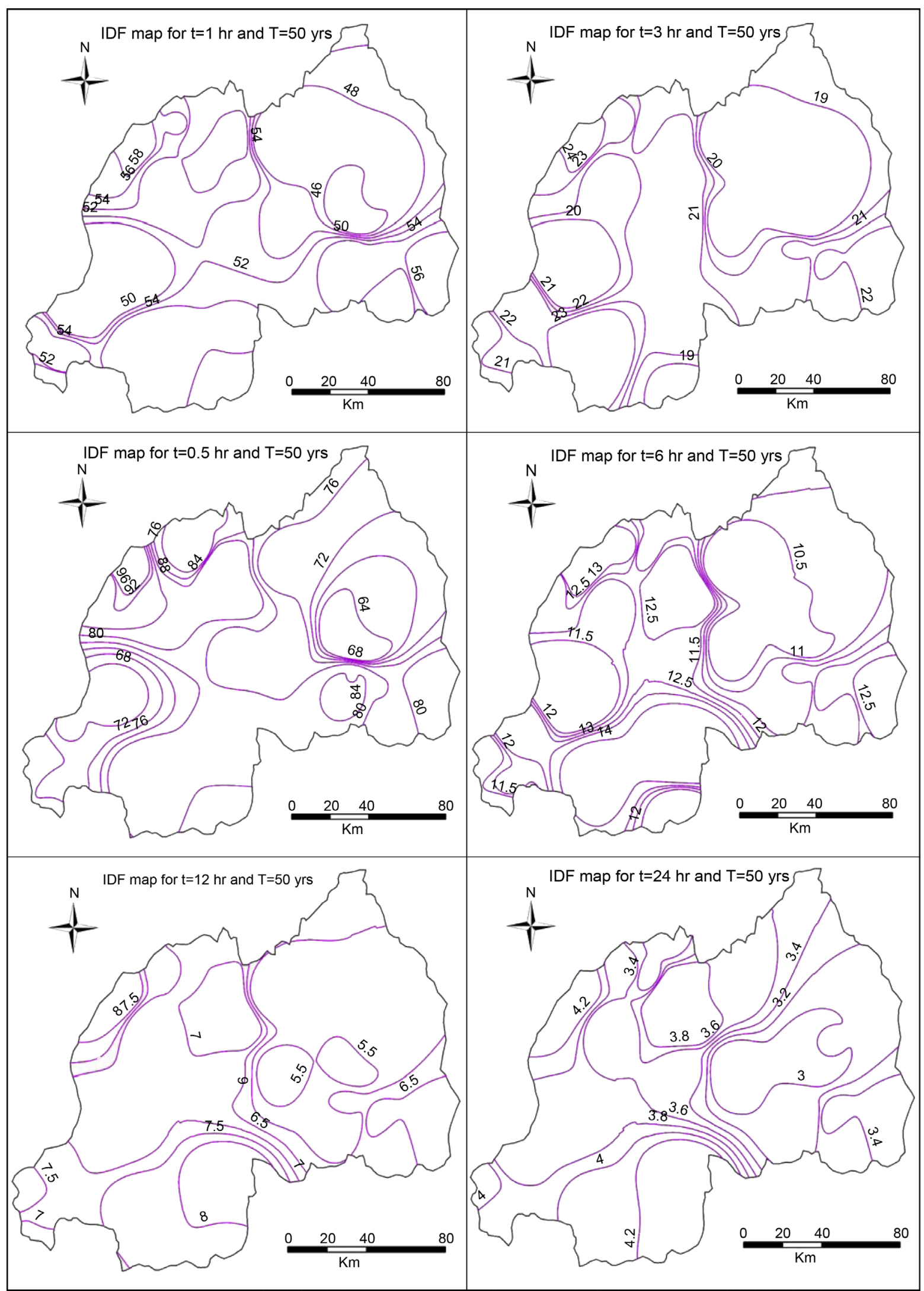

(c) 


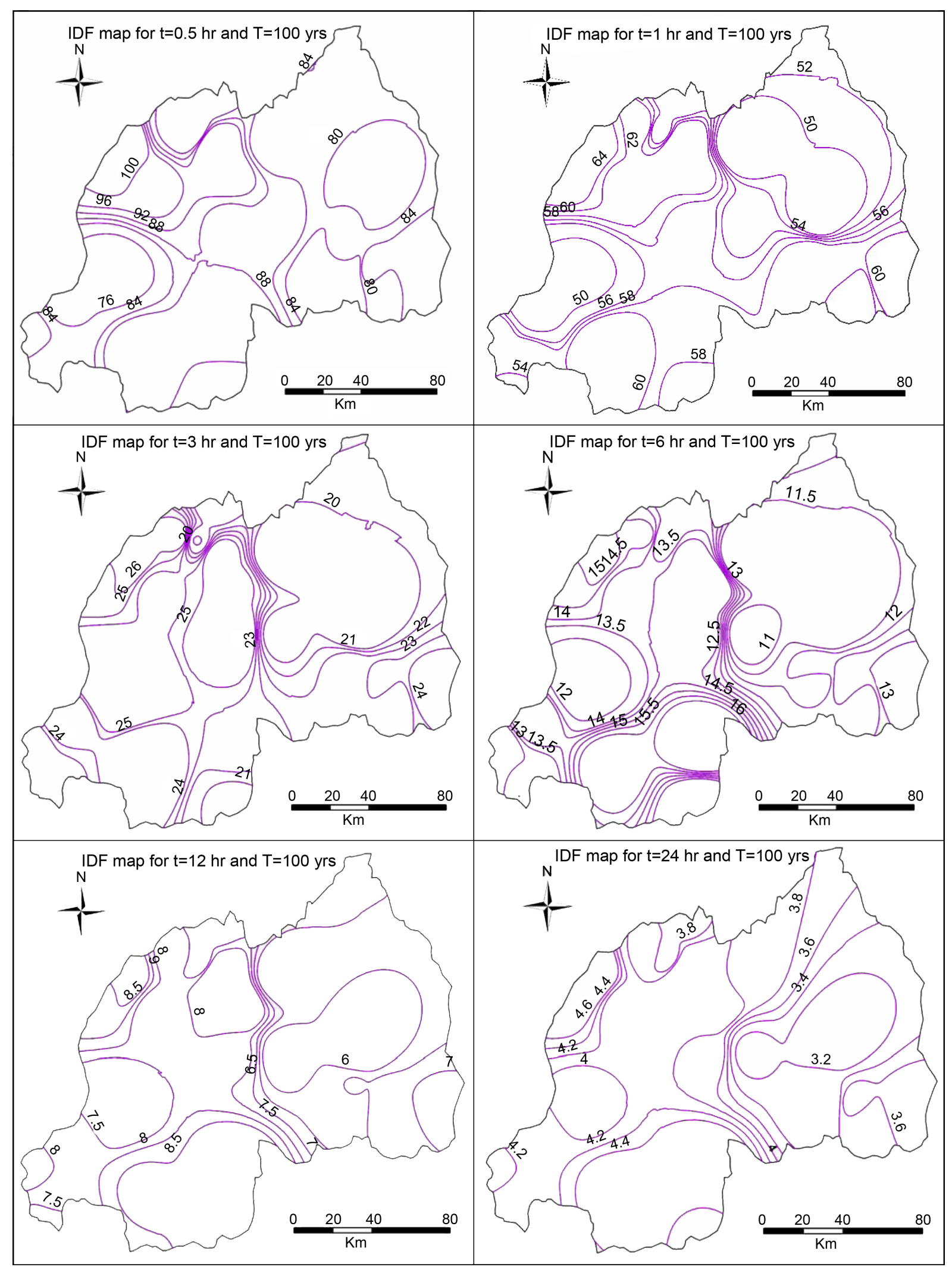

(d)

Figure 4. (a) (b) (c) (d) IDF map of Rwanda for selected rainfall durations and return period. 


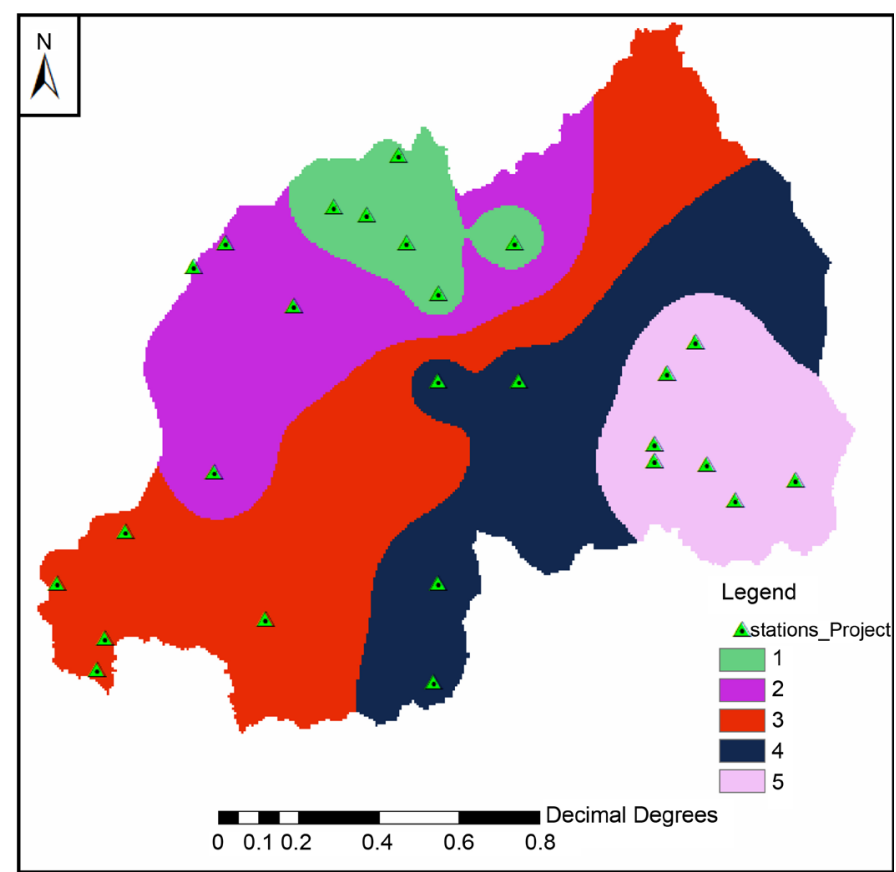

Figure 5. Homogeneous regions identified based on rainfall frequency analysis.

Table 3. LMRD and MRD based station clustering.

\begin{tabular}{ccc}
\hline \multicolumn{1}{c}{ Region } & \multicolumn{1}{c}{ Stations } & Fitting Distribution \\
\hline Region-1 & Bulera, Byumba, Nemba, Ruhengeri, Rushashi and Rwaza & Generalized logistic \\
Region-2 & Busasamana, Gisenyi, Gishyita and Kabaya & Gamma \& Pearson Type-II \\
Region-3 & Bugarama, Kamembe, Kitabi, Nyamasheke and Nyakabuye & Generalized extreme Value \\
Region-4 & Gakoma, Gitega, Kabaya, Kigali and Nyamiyaga & Generalized extreme Value \\
Region-5 & Gahini, Karama, Kibungo, Nyarubuye, Nyamata, Rwamagana and Zaza & Gamma \& Pearson Type-II \\
\hline
\end{tabular}

Table 4. Regional IDF parameters.

\begin{tabular}{|c|c|c|c|c|c|c|c|}
\hline Region & Parameters & $T=2 \mathrm{yrs}$ & $T=5 \mathrm{yrs}$ & $T=10 \mathrm{yrs}$ & $T=25 \mathrm{yrs}$ & $T=50$ yrs & $T=100 \mathrm{yrs}$ \\
\hline \multirow{3}{*}{ Region 1} & $\alpha$ & 1649.52 & 1737.75 & 1847.72 & 1894.85 & 1895.00 & 2278.12 \\
\hline & $\gamma$ & 20.56 & 17.33 & 15.92 & 13.14 & 10.09 & 13.67 \\
\hline & $C$ & 0.91 & 0.89 & 0.88 & 0.86 & 0.85 & 0.86 \\
\hline \multirow{3}{*}{ Region 2} & $\alpha$ & 983.74 & 1112.82 & 1095.21 & 1375.48 & 1566.78 & 1861.69 \\
\hline & $\gamma$ & 4.85 & 4.85 & 2.20 & 3.15 & 3.15 & 4.85 \\
\hline & C & 0.83 & 0.81 & 0.79 & 0.81 & 0.82 & 0.83 \\
\hline \multirow{3}{*}{ Region 3} & $\alpha$ & 976.75 & 1390.01 & 1401.19 & 1590.16 & 1784.72 & 2237.48 \\
\hline & $\gamma$ & 10.62 & 15.94 & 13.85 & 13.70 & 14.96 & 17.33 \\
\hline & C & 0.84 & 0.86 & 0.84 & 0.84 & 0.84 & 0.86 \\
\hline \multirow{3}{*}{ Region 4} & $\alpha$ & 724.64 & 847.46 & 994.08 & 1076.6 & 1133.46 & 1983.76 \\
\hline & $\gamma$ & 3.15 & 2.36 & 3.15 & 2.19 & 0.62 & 9.23 \\
\hline & $C$ & 0.79 & 0.78 & 0.78 & 0.77 & 0.76 & 0.83 \\
\hline \multirow{3}{*}{ Region 5} & $\alpha$ & 729.58 & 976.10 & 1145.79 & 1389.89 & 1690.38 & 1661.38 \\
\hline & $\gamma$ & 3.09 & 4.85 & 4.85 & 5.62 & 7.29 & 4.84 \\
\hline & $C$ & 0.81 & 0.81 & 0.82 & 0.82 & 0.84 & 0.82 \\
\hline
\end{tabular}



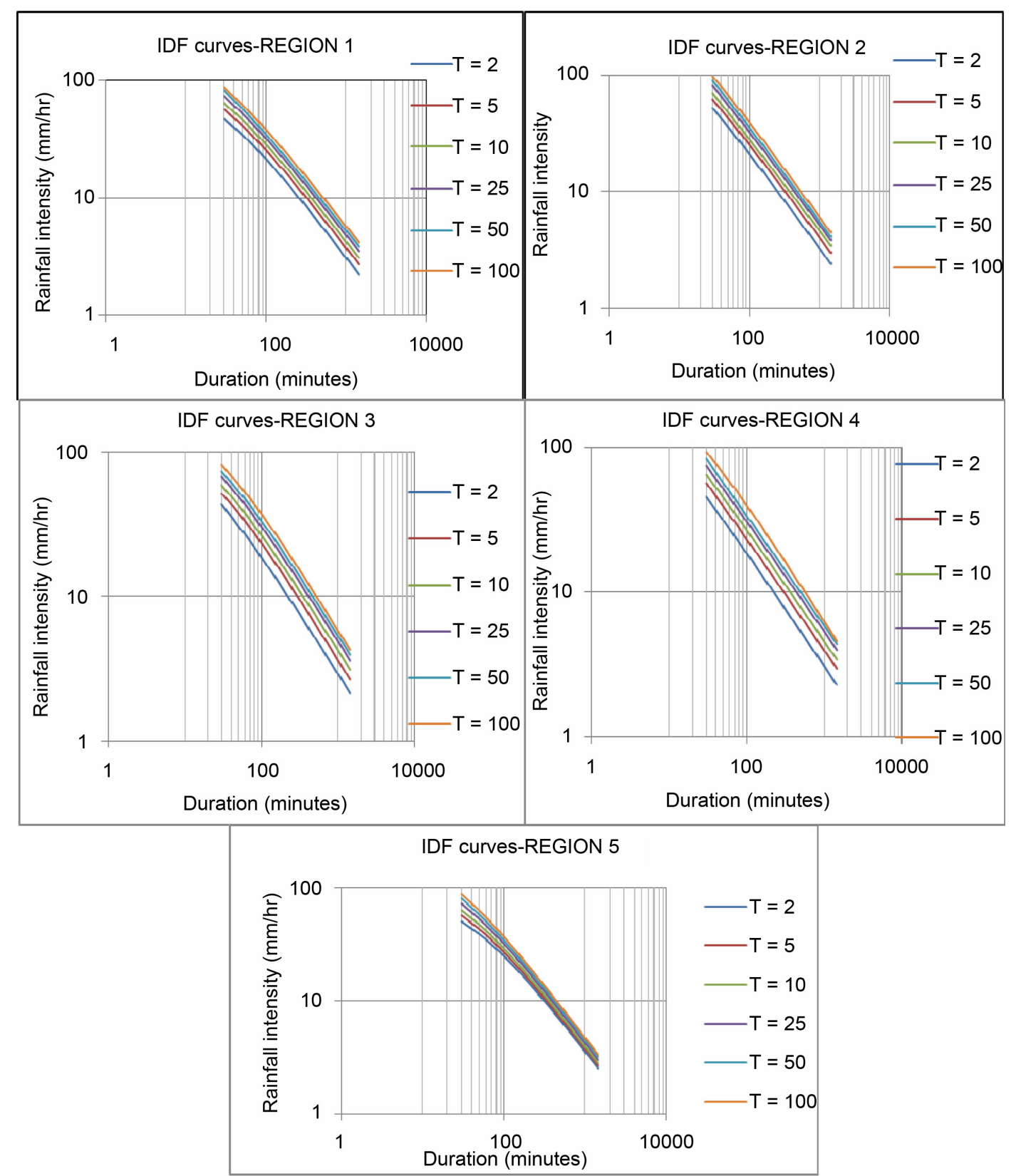

Figure 6. Regional IDF curves for selected return period.

Table 5. Regional quantile (mean of stations) for the selected duration.

\begin{tabular}{cccccccc}
\hline Return Period & $\mathbf{0 . 5} \mathbf{~ h r}$ & $\mathbf{1} \mathbf{~ h r}$ & $\mathbf{3} \mathbf{~ h r}$ & $\mathbf{6} \mathbf{~ h r}$ & $\mathbf{1 2} \mathbf{~ h r}$ & $\mathbf{2 4} \mathbf{~ h r}$ \\
\hline $2 \mathrm{yr}$ & 23.1 & 31.8 & 38.9 & 45.7 & 50.5 & 52.5 \\
$5 \mathrm{yrs}$ & 27.9 & 38.2 & 46.1 & 54.7 & 60.0 & 65.0 \\
$10 \mathrm{yrs}$ & 31.5 & 42.9 & 51.4 & 60.8 & 68.7 & 73.1 \\
$25 \mathrm{yrs}$ & 36.1 & 48.4 & 57.6 & 68.7 & 77.7 & 83.7 \\
$50 \mathrm{yrs}$ & 40.2 & 52.8 & 62.7 & 74.0 & 84.9 & 91.4 \\
$100 \mathrm{yrs}$ & 42.7 & 57.6 & 68.4 & 81.0 & 93.2 & 99.3 \\
\hline
\end{tabular}




\section{Conclusions}

Theoretical probability distribution for the 24-hr annual maximum rainfall depths for different durations has been selected using moment ratio and L-moment ratio diagrams methods. Based on the least standard error of estimate, best fitted probability distributions are identified and subsequent quantiles have been computed for different return period. Rainfall IDF parameters for selected duration and recurrence interval are computed for all stations under consideration. The adequacy of computed rainfall intensities are evaluated through statistical analysis against the observed values. The results of these tests indicated that the estimated IDF parameters adequately represented the rainfall intensities for most of the stations.

Rainfall station clustering has been made taking into account the annual maximum rainfall depth of 24-hr duration. The best fitted distribution for each homogeneous regions were identified based on statistical values of LCs and LCk of annual maximum rainfall depth for all implied stations. Based on MRD and LMRD analysis, the rainfall stations are categorized into five homogeneous regions. The rainfall stations clustered within a region sufficiently satisfied the homogeneity test. Identified regional parameters are representative of the at-site information for longer rainfall durations, however, deviation from the regional parameters is observed for shorter rainfall duration in some regions.

Available automatic rainfall stations are very limited in number and most of the regions have got a short rainfall record (less than five years). Therefore, developing IDF map from existing information through statistical analysis may be subjected to imprecision and prone to certain errors. Future water resources planning and design studies should rely on reliable observed rainfall data from automated stations to develop IDF maps.

\section{References}

[1] Mohymont, B.G. (2004) Establishment of IDF-Curves for Precipitation in the Tropical Area of Central Africa. Natural Hazards and Earth System Sciences, 4, 375-387. http://dx.doi.org/10.5194/nhess-4-375-2004

[2] Lam, K. (2004) Update of the Short Duration Rainfall IDF Curves for Recent Climate in Quebec. Canadian water Res. Assoc. Ann. cong.

[3] Koutsoyiannis, D.K. (1998) A Mathematical Framework for Studying Rainfall Intensity-Duration-Frequency Relationships. Journal of Hydrology, 206, 118-135. http://dx.doi.org/10.1016/S0022-1694(98)00097-3

[4] Koutsoyiannis, D. (2003) On the Appropriateness of the Gumbel Distribution for Modelling Extreme Rainfall. Proceedings of the ESF LESC Exploratory Workshop, Hydrological Risk: Recent Advances in Peak River Flow Modelling, Prediction and Real-Time Forecasting, Assessment of the Impacts of Land-Use and Climate Changes, European Science Foundation, National Research Council of Italy, University of Bologna, Bologna.

[5] Nhat, L., Tachikawa, Y. and Takara, K. (2006) Derivation of Rainfall Duration Frequency Relationship for Short Duration Rainfall from Daily Rainfall. Proc. of Int.l Symp. on Managing Water Supplyfor Growing Demand, Technical Document in Hydrology, 6, 89-96.

[6] Prodanovic, P. and Simonovic, S.P. (2007) Development of Rainfall Intensity Duration Frequency Curves for the City of London Under the Changing Climate. Water Resources Research Report No. 058, Facility for Intelligent Decision Support, Department of Civil and Environmental Engineering, London, Ontario, Canada, 51 p.

[7] Khalid, K. and Elsebaie, I. (2013) Development of Intensity Duration Frequency Relationship for Abha City in Saudi Arabia. International Journal of Computer Engineering Research, 3, 58-65.

[8] Bernard, M. (1932) Formulas for Rainfall Intensities of Long Duration. Trans.ASCE, 96, 592-624.

[9] Chow, V., Maidment, D. and Mays, L. (1988) Applied Hydrology. McGraw-Hill Book Company, New York.

[10] De Paola, F., Giugni, M., Topa, M.E. and Bucchignani, E. (2014) Intensity Duration Frequency (IDF) Rainfall Curves, for Data Series and Climate Projection in Africa Cities. Springer Plus, 3, 133. http://dx.doi.org/10.1186/2193-1801-3-133

[11] Ben-Zvi, A. (2009) Rainfall Intensity-Duration-Frequency Relationships Derived from Large Partial Duration Series. Journal of Hydrology, 367, 104-114. http://dx.doi.org/10.1016/j.jhydrol.2009.01.007

[12] Bougadis, J. and Adamowski, K. (2006) Scaling Model of Rainfall Intensity-Duration-Frequency Relationship. Hydrological Processes, 20, 3747-3757. http://dx.doi.org/10.1002/hyp.6386

[13] Cheng, L. and Agha Kouchak, A. (2014) Nonstationary Precipitation Intensity-Duration-Frequency Curves for Infrastructure Design in a Changing Climate. Scientific Reports, 4, 7093, 1-6.

[14] Climate Report, Rwanda (2009) DFID Economic Impacts of Climate Change: Kenya, Rwanda, Burundi, ICPAC, Kenya and SEI Oxford Office. 
[15] REMA, Ruwanda Environmental Managemnent Authority (2006) Rwanda State of Environment and Outlook. Kigali.

[16] Wenzel Jr., H.G. (1982) Rainfall for Urban Stormwater Design, Urban Stormwater Hydrology, Water Resour. Monogr., 7D. F. Kibler, AGU, Washington DC.

[17] Dalrymple, T. (1960) Flood Frequency Analysis. US Geological Survey. Water Supply Paper, 1543 A.

[18] Grover, P.L., Burn, D.H. and Cunderlik, J.M.A. (2002) Comparison of Index Flood Estimation Procedures for Ungauged Catchments. Canadian Journal of Civil Engineering, 29, 734-741. http://dx.doi.org/10.1139/102-065

[19] Hosking, J.R.M. (1990) L-Moments: Analysis and Estimation of Distributions Using Linear Combinations of Order Statistics. Journal of the Royal Statistical Society, Series B, 52, 105-124.

[20] Atiem, A. and Harmancioglu, N.B. (2006) Assessment of Regional Floods Using L-Moments Approach: The Case of the River Nile. Water Resources Management, 20, 723-747. http://dx.doi.org/10.1007/s11269-005-9004-0

[21] Gonzalez, J. and Valids, J.B. (2008) A Regional Monthly Precipitation Simulation Model Based on an L-Moment Smoothed Statistical Regionalization Approach. Journal of Hydrology, 348, 27-39. http://dx.doi.org/10.1016/j.jhydrol.2007.09.059

[22] Saif, B. (2009) Regional Flood Frequency Analysis Using L-Moments for the West Mediterranean Region of Turkey. Water Resources Management, 23, 531-551. http://dx.doi.org/10.1007/s11269-008-9287-z

[23] Burn, D.H. (1988) Delineation of Groups for Regional Flood Frequency Analysis. Journal of Hydrology, 104, $345-361$. http://dx.doi.org/10.1016/0022-1694(88)90174-6

[24] Cavadias, G.S. (1989) Regional flood Estimation by Canonical Correlation. Paper Presented to the 1989 Annual Conference of the Canadian Society for Civil Engineering, St-John's, Newfoundland.

[25] Hosking, J.R.M and Wallis, J.R. (1997) Regional Frequency Analysis: An Approach Based on L-moments. Cambridge University Press, UK. http://dx.doi.org/10.1017/cbo9780511529443 